\title{
The Ecotourism Development in Guizhou
}

\author{
Xiao Wang ${ }^{1, a}$ \\ ${ }^{1}$ The Chinese University of Hong Kong \\ achloe__wong@hotmail.com
}

\section{Keywords: Ecotourism Guizhou Pro-poor Tourism}

\begin{abstract}
.uizhou is a poor and economy undeveloped province, but rich in nature, cultural and environmental resources. Guizhou has the advantages and potential to develop ecotourism. This study will introduce the approaches and evaluate the implementation of the ecotourism development in Guizhou.
\end{abstract}

\section{Introduction}

Guizhou province is located in the southwest of China. The capital city is Guiyang, and it is a mountainous province, the climate of Guizhou is very humid and comfortable for people to live because there are few seasonal changes. There are lots of ethnic minorities in Guizhou, and minority groups there are more than $37 \%$ of the population, and also $55.5 \%$ of the province area is designated as autonomous regions for ethnic minorities. (Liao Shanyou, 1997) Guizhou is a poor and economy undeveloped province, but rich in nature, cultural and environmental resources.

Guizhou province is rich in nature resources and minority cultures, the undeveloped heavy industry and transportation system protected the nature resources so that it is maintaining the original appearance, so Guizhou has the advantage to develop ecotourism. Another reason for Guizhou to develop ecotourism is because that ecotourism does not need to invest a lot of money. Ecotourism does not need to construct too many facilities. (Deng Yinghong, 2006) The government made some tourism polices in order to reduce the poverty of Guizhou. The central government encourages Guizhou to develop tourism to improve their living standard and stimulate economic growth.

Ecotourism is one of the methods to realize sustainability. Ecotourism can also have positive effects on natural sustainability, cultural sustainability and economic sustainability.

\section{The approaches}

Guizhou has abundant nature resources and ethnic culture, which is the core competitiveness of developing ecotourism in Guizhou. The government should make full use of its advantages. Highly urbanized life makes the minority life more attractive, people want to escape from the urban life to enjoy the peace and relax them in countryside. It means the market led the ethnic countryside to develop ecotourism. The minorities in Guizhou have more than four hundreds ethnic festivals to celebrate, which is also very attractive to tourists. The National Tourism Administration set 1999 as 
"ecological tourism year". After 1999, some areas in China began to develop ecotourism. We can see the visitor number of Guizhou increased dramatically in 2004 from Fig. 1(Deng Yinghong, 2006).

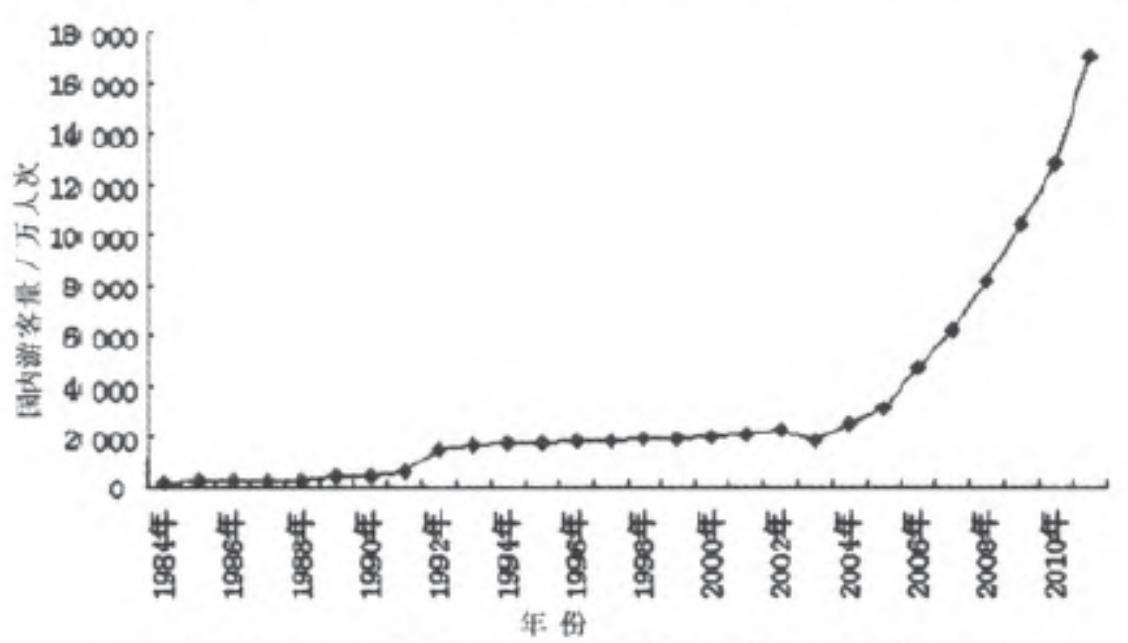

图1 1984-2011 年贵州省国内游客量数据图

Fig. 1: 1984—2011 The number of domestic tourism visitors of Guizhou (Deng Yinghong, 2006)

\section{The implementation of ecotourism in Guizhou}

Tourism is the crown of the world economy, which can contribute 4.4\% GDP for the whole world economy every year. Ecotourism is the guarantee of the tourism industry. It's also the trend of tourism development. Ecotourism is a very vigorous industry because it increases $30 \%$ every year. (Zhao Jun, 2006)

We can see the dramatic increase in Fig. 1, it shows that the tourism visiting number had nine times leap in 2010 compared with that in 2004. The increasing visitors make profits to local community was increasing, we can see the specific information from Table 1(Zhang Jie, 2012).

Table 1: the tourism income of Guizhou from 2002 to 2011 (Zhang Jie, 2012)

\begin{tabular}{|l|l|l|l|l|l|l|l|l|l|l|}
\hline \multicolumn{1}{|c|}{ Year } & 2002 & 2003 & 2004 & 2005 & 2006 & 2007 & 2008 & 2009 & 2010 & 2011 \\
\hline $\begin{array}{l}\text { Income/10thd } \\
\text { dollars }\end{array}$ & 7951 & 2894 & 8020 & 10141 & 11516 & 12918 & 11697 & 11044 & 12958 & 13507 \\
\hline $\begin{array}{l}\text { Visiting } \\
\text { number/10thd }\end{array}$ & 22.8 & 7.7 & 23.1 & 27.6 & 32.1 & 43.0 & 39.5 & 40.0 & 50.0 & 58.5 \\
\hline
\end{tabular}

The tourism visiting number of Guizhou dropped in 2003 it was because the outbreak of SARS, except that special period the total trend of income and visiting number all increased.

Eco-forum Global Guiyang put forward a declaration of ecological civilization and sustainable tourism development Guiyang on 11 July, 2014. It is a mark of the development of sustainable 
tourism in China. UNDP,UNEP,UNESCO, WWF and more than 25 international authority organizations attend the forum, which means they fully recognize this forum and theachievements of sustainable tourism development in China.

The central government proposed a strategy that is to develop Guizhou as a culture tourism Innovation area, which is trying to combine the ethnic culture and sustainable tourism. Put great efforts to build Guizhou into international tourism leisure restore even holiday paradise.(Wang Ziping, 2014) In order to achieve this strategy goal, different tourism attractions in Guizhou proposed some specific plans thoseare suitable for their actuality of developing culture tourism or ecotourism. The LongXingShenZhou travel group introduced 106 pure electric vehicles to instead the traditional bus, which can reduce the PM2.5 and carbon dioxide 3290 tons every year. Mountain Leiorganized a festival event called The Miao New Year of Lei Mountain. This festival event was consisting of a serious ethnic culture dance and sing competitions, which attracted lots of tourists to have a visit.

\section{Who get the most benefits?}

There are two major stakeholders of developing tourism industry, one is the tourism operator the other is the local communities. Besides those two major stakeholders, I think the local ecological system also can get great benefit from the ecotourism developing, which is more important than just generate some economic benefits.

The developed transportation system is the basic condition for developing tourism, so the local infrastructure will be improved because of the tourism developing. The local communities can get benefits from the highly developed transportation system, it will be more convenient for them to communicate with the outside world, they can trade with outside which can generate economic benefits as a way to increase their incomes, besides that they also can import some new things to improve their life quality. Another important benefit is that the local children can have opportunities to get access to high quality education, which is the future of the local community because the quality of younger generation can decide the fate of the local community.

Some local residents are also involved in the tourism commercial businesses, some of them can run a restaurant to provide some local food for tourists, and some others sell the local handmade souvenirs to tourists. Besides those businesses, some residents also converted their house into hostel for tourists.

There are also some local residents can get a job from the tourism attractions which is also a method to increase local employment rate.

Without any suspicion, the tourism developer, which is also the tourism operator, will share the most economic benefit of local tourism development. After all they invested a lot of money in construction infrastructure and planning works before.

The local environment can be protected, which can generate the ecological benefits. There are more the 1700 nature conservation areas was built because the development of sustainable tourism. Another environmental challenge is that because of the local residents are lacking of environmental awareness, so they cut trees as fuel to cook or to keep warm. With the development of tourism in 
that areas, the gas and other fuels was introduced and their income was improved by involving in tourism businesses, so they do not need to use trees as fuels any more, which can also protect the environment. (Zhao Jun, 2006) The ecological benefit is not only an important factor for tourism development but also the basic guarantee for the local region development.

The extent of local community has been involved in decision-making

Tourism developing is relying on the local community, and the extent of local community has been involved in is a very important criteria to evaluate the local tourism development of sustainability. (Hu Zhiyi, 2002) The local community is the core of local tourism development; a good participation of local community can create a positive tourism image for visitors and also can extend the lifecycle of the resort.

The degree of local community involvement in tourism development can be divided into four stages, the first one is the Individual Participation; the second one is the Organized Participation; the third one is Mass participation; the last one is the Full Participation. (Hu Zhiyi, 2002) The different stages of local community involvement in tourism development has different scales and problems, I will introduce those problems by Table 2. (Hu Zhiyi, 2002)

Table 2: The phase features of community involvement into tourism industry

\begin{tabular}{|l|l|l|l|}
\hline $\begin{array}{l}\text { Involvement } \\
\text { Stages }\end{array}$ & \multicolumn{1}{|c|}{ Scales } & Main Content & $\begin{array}{l}\text { Environmental or } \\
\text { Social problems }\end{array}$ \\
\hline $\begin{array}{l}\text { Individual } \\
\text { Participation }\end{array}$ & $\begin{array}{l}\text { Individual } \\
\text { residents }\end{array}$ & Not-for-profit activities & Almost no \\
\hline $\begin{array}{l}\text { Organized } \\
\text { Participation }\end{array}$ & $\begin{array}{l}\text { Some } \\
\text { Organized } \\
\text { residents }\end{array}$ & For-profit activities & Appears \\
\hline $\begin{array}{l}\text { Mass } \\
\text { participation }\end{array}$ & $\begin{array}{l}\text { A majority of } \\
\text { residents }\end{array}$ & $\begin{array}{l}\text { For-profit activities, and also } \\
\text { conserve the environment. }\end{array}$ & $\begin{array}{l}\text { Increasingly } \\
\text { prominent }\end{array}$ \\
\hline Full Participation & $\begin{array}{l}\text { All residents, } \\
\text { Unprompted }\end{array}$ & $\begin{array}{l}\text { Full range activities of economy, } \\
\text { environment and society. }\end{array}$ & $\begin{array}{l}\text { All the problems are } \\
\text { under control and } \\
\text { develop in harmony }\end{array}$ \\
\hline
\end{tabular}

The extent of local community involvement develops as an "S” (Fig. 2) (Hu Zhiyi , 2002 ): At the first stage, Individual Participation, it's very easy to be involved in tourism industry, but the participation scales and tourism incomes are all very low, the environmental problems are also very little during that time. From the second organized participation stage to the third mass participation stage, the scales surged during those stages. When entering the final full participation stage, the competition becomes very intense; the local residents have to compete with each other in order to grab business opportunities. There will be two consequences of the local community involvement in tourism industry. On one hand, all the factors develop in harmony, and the lifecycle of the resort will be extended, the local residents well participate in tourism develop process. On the other hands, the developers still ignore the local community's voice and the commercial competition becomes imbalance, so the community participation interest drops. 


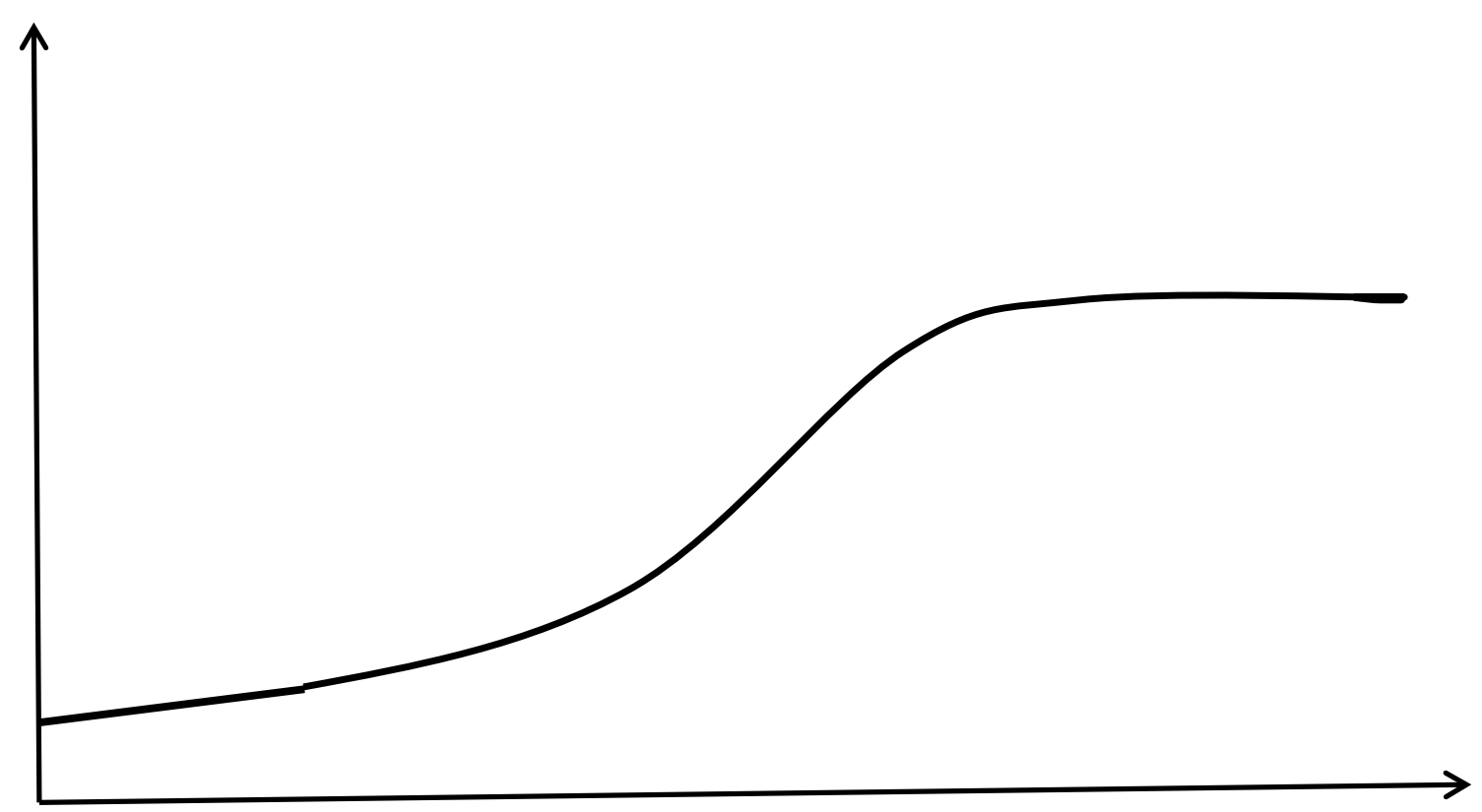

Fig. 2: The curve similar with "S" of community involvement

The local community in Guizhou is just in the second stage or third stage, the participant level is not very high. (Yang Xi, 2012) The local community has few opportunities to be involved in decision-making process, which is because that the decision-making process is very powercentralized, both the government and the tourism operators are all think the local residents are not well educated so they cannot provide useful tourism development suggestions. So it can be recognized that the local residents are marginalized by decision-making institution. (Song Rui, 2005) This problem may cause by the political system in China, which is the top-down decision-making process. The most important problem is that kind of conception is highly accepted by the local residents, the local residents in China are not confident enough to speak out their idea. They think that making decision is a very complicated and holy process which can only be done by experts, and even some of them may think the making decision process is none of their business, so they give up their rights to participate in decision-making process.

I cannot agree with their opinions, I think the local residents know the local advantages, disadvantages and the potential problems better than some researchers, so their voice cannot be ignored.

\section{Conclusion}

Developing sustainable tourism in Guizhou is a very wise choice, which can make full use of its advantages and avoiding some disadvantages in the meantime. Developing sustainable tourism in Guizhou is also encouraged by central government, and the investment has increasedof $248.83 \%$ in past five years. (LU Yueyue, 2003) The GDP of Guizhou province increased a lot during this time, which cannot achieve without the contribution of tourism industry. The world average economic 
benefits of sustainable tourism increased 30\% every year (Zhao Jun, 2006), and Guizhou even has larger potential.

The tourism industry of Guizhou is developing. Although there are also some problems need to be improved, the sustainable tourism of Guizhou develops very well, which can not only reduce the poverty of the area, but also can conserve the local environment in the meantime. The sustainable tourism can also have positive effects on local economic development, local ecologic system and also local social development. I think the other provinces which are rich in nature resources can learn some useful experience of sustainable tourism development from Guizhou. The sustainable development is the guideline for all industry, not only the tourism industry. Only in this way, can we develop longer and better.

\section{References}

1.Li, Z., 1950-, Meng, J., \& Gao, L. (2008). Tourism of GuiZhou : China Science Culture Publishing House; Hong Kong.

2. LU Hai-mei, Liao Jihong. (2010). The development of Guizhou tourism industry should play the " National brand " .The culture study of Guizhou, (4), 85-88.

3. Liao Shanyou. (1997).Tourism of Guizhou. Gui Yang: Guizhou Ethnic Publishing House.

4.Cheng Jiaquan,Wen Wei,Zhang Xu. (2010). The study of tourism sustainability for reducing poverty of Guizhou,(22), 29-30.

5. YANG Yuan,Liu, Qingyou. (2010). Discussion on farming culture of ethnic villages in guizhou tourism. Guangdong Agricultural Sciences, 37(7), 234-235.

6. Lin Qian Zhi. (2010).GuiZhou tourism development issues and resolution. Journal of Gui Yang Municipal School,(4), 35-37.

7. Wang Xianqing. (2011). The current problems and reasons of Guizhou tourism based on field research. Business and Economy, (8), 58-59.

8. Tian Weixu. (2005). A sociological analysis of the causes of non- continuation issue in ethnic tourist consumption. Journal of Guizhou Ethnic College (6), 75-79.

9. Nelson, H. Graburn, Anthropological comments on sustainable development of tourism in china. The Journal of Tourism, 21(1), 54-59.

10.ZHAO Nan, Zhang Sulin(2009). Study on the tourism development strategy of Dazhou. Journal of Jingchu University of Technology, 24(11), 59-63. 